\title{
Water Content in Food Drink and IL-10 Level Rosa Lelyana ${ }^{1} *$ \\ ${ }^{1}$ Faculty of Diponegoro University, Indonesia. \\ *Corresponding E-mail: rl3lyana@gmail.com
}

\begin{abstract}
Introduction: Water affects IL-10 levels in the body. Many people do not understand that water is very important and needed by the body for influencing IL-10 levels. The purpose of writing this paper is to be able to understand the importance of water for the body on IL-10 levels in order to avoid various conditions that interfere with health. Method: Review study. Results: The simplest but most important source of nutrients is water. The water content in the body is about $60-70 \%$, and a loss of about $10 \%$ of the water will cause death. Water balance is obtained through food, drink, and the body's metabolic processes. Various components of food and beverages consumed such as coffee drinks, vegetable soups/fruit juices contain water and affect IL-10 levels in the body. Likewise, the water content in bath water and various other daily activities affect IL-10 levels in the body. Discussion: Vegetables, even drinks such as coffee contain water so that they can fulfill the body's health functions, both for skin health, all body organs and body tissues and cells, as well as for metabolic functions and avoiding dehydration conditions. The water content in the food we drink and the water we use greatly affects the condition of the body so that it also affects the body's immune response. This is related to the presence of IL-10 levels where the increase and decrease in IL-10 levels are strongly influenced by the components of the food or drink contained in the water or the water content contained in the food and drink. In fact, bathwater containing sulfur also affects IL-10 levels. So water plays an important role in IL-10 levels in the body. Conclusions: Body health is influenced by water and water also affect IL-10 levels in the body so that it is beneficial for body health related to the immune system.
\end{abstract}

Keywords: Health, Fluid, Water, Food, Drink, Interleukin 10.

Received: 03 September, 2021

Accepted: 11 September, 2021

Published: 17 September, 2021

\section{Introduction}

Water is needed by the body in various healthy life functions. Health is very important for our life. Food and beverage products contain water. Even skin beauty and body health really need water to avoid dehydration and various other health problems/metabolic disorders. IL-10 is an anti-inflammatory cytokine that the body needs to maintain the immune system.

Health is very important for the body. Water greatly affects the life and health of the body. Water is important for our life because all humans need water for their survival [1]. In addition to being important for our lives, water also has an important effect on the health of our bodies, so that the right use of water for the body will be able to prevent the occurrence of various diseases, both infectious and non-communicable diseases, water-related nutrition [2]. Likewise, improper use of water will cause problems for our lives. Water has various functions in our life. There are so many benefits of water, namely to help the functions of excretion, metabolism, transportation, absorption, 
digestion, assimilation. In addition to helping all the functions above, water is related to the growth and development of body cells. In addition, water is needed by body cells because part of our body is filled with water. Water is needed by the body for daily life. Even bathing we use water up to 2 times a day. Water is also used to cook food and drinks, where clean water sources from wells and tap water/PAM greatly affect the body's condition. Hygiene and water sanitation also need to be considered, even when consuming water or using it for daily activities as well as bathing. Water is related to the body's metabolic functions, growth and development of body cells and skin cells as well as all other body cells and also to avoid emergency conditions so that the body does not lose water which causes dehydration.

Interleukin 10 is a family of anti-inflammatory cytokines that are required for the body's immune response. Consumption of food and beverages and the water content in them affect IL-10 levels so that they can increase or decrease IL-10 levels. Every food contains a water component, so do drinks. So that the water content in the food or drink will provide the potential for an increase in IL-10 levels or a decrease in IL-10 levels. Foods that contain lots of water, especially foods that contain vegetables and fruits.

Many people do not understand the health benefits of water content for the body on IL-10 levels. Therefore, in this paper, we will discuss the health benefits of daily water content in some foods/drinks and the health effects of water content on IL-10 levels in the body.

\section{Methods}

This manuscript is arranged by systematic review, dimana pencarian kata kunci menggunakan Google Scholar. The journals used in the search for articles were indexed by PubMed and PloS One. From the search results found 50 journal articles and those that meet the writing criteria related to keywords found 31 journal articles. The food and drinks listed in the image below are documented private files from the author and dishes that are personally processed with the author's personal concoctions but have been shown on social media photos.

\section{Results and Discussion}

\section{A. Water Content for Food Products Related to IL-10 Level for Human Health}

Foods that contain water for example are tomato spinach soup. This vegetable soup also consists of spinach, tomatoes, shrimp, meatballs which are all processed with a variety of seasonings to taste delicious but healthy (Figure 1).

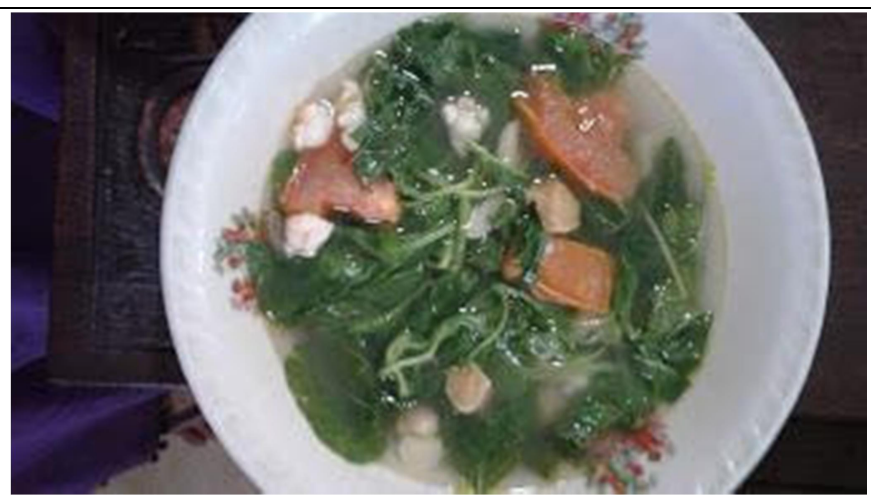

Figure 1: Documented Private File from Dr Rosa Lelyana. This photo was shared by Dr Rosa Lelyana. In her Social Media few years ago, but have not shared in the journals international. The name of this soup is Sayur Bayam Ca Udang in Indonesia language. This food's picture was cooked by Rosa Lelyana MD, MSi Med, SKed, PhD. 
Other foods that contain water are stir-fried spices in tomatoes and other vegetables as well as eggs, meat, and other variations of protein and vegetables.

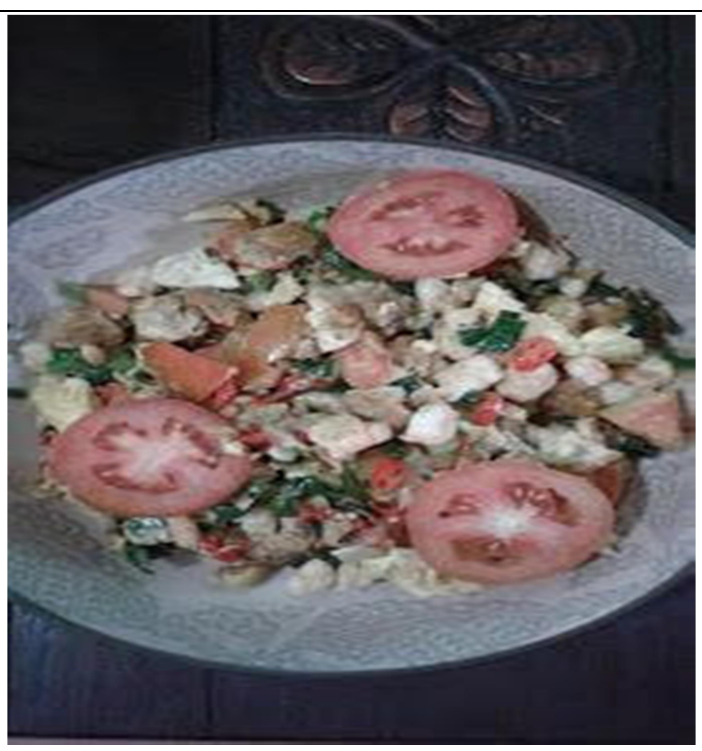

Figure 2: Documented Private File from Dr Rosa Lelyana. This photo was shared by Dr Rosa Lelyana. In her Social Media few years ago, but have not shared in the journals international. The name of this cooking is Tumis Sayur with Tomato etc in Indonesia language. This food's picture was cooked by Rosa Lelyana MD, MSi Med, SKed, PhD

Mineral water in this food menu is contained in tomatoes which also provide health benefits for our bodies. One study showed that tomato and carrot water extracts reduced COX-2 and TNF- levels, while carrot water extracts alone showed increased levels of IL-10 cytokines that act as an anti-inflammatory [3]. Consumption of water with meat, eggs, vegetables, and protein variations such as shrimp or consumption of foods of this type that contain meat, fish, cereals, and fiber or contain lots of fiber and non-fiber, the fiber content provides a protective effect against rectal colon carcinogenesis in humans. Individuals with IL-10 are genetically sensitive to the presence of Colon Rectal Cancer. In other words, an interaction between IL-10 and fiber consumption was found in Colon Rectal Cancer Carcinogenesis [4].

Other foods containing water and vegetables are tomato ketchup, where consumption of tomato ketchup will reduce gene expression and pro-inflammatory production of TNF- $\alpha$ and IL-8, as well as increase levels of the antiinflammatory cytokine IL-10 [5]. It is known that tomatoes and tomato products are associated with a reduced risk of developing inflammatory diseases, namely atherosclerosis where tomatoes act as a protective factor or prevent the occurrence of atherosclerosis and other inflammatory diseases [5-7].

Inflammation is triggered by bacteria or tissue damage caused by the activation of Nuclear Factor Kappa Beta (NF$\mathrm{kB}$ ) which promotes the expression of several pro-inflammatory genes and the release of anti-inflammatory cytokines such as IL-10 [8]. Oxidative stress can initiate the inflammatory process by activating pro-inflammatory cytokines and NF-kB. Lycopene contained in tomatoes inhibits the activity of NF-kB [8, 9]. It should be emphasized once again that tomato products such as tomato juice, tomato soup, and tomato paste are able to protect against cardiovascular disease because they contain bioactive compounds in the form of carotenoids, flavonoids, and vitamins such as vitamin ascorbic acid and -tocopherol which can inhibit pro-inflammatory activity as well as inhibits NF-B [10]. 


\section{B. Water Content for Drink Products Related to IL-10 Level for Human Health}

In addition to food, among drinks that contain water are coffee drinks. In a cup of coffee, in addition to water content, there is also coffee content. Coffee contains antioxidants that can fight oxidants from our body that come from pollutants and body metabolites resulting from our body's metabolism [11].

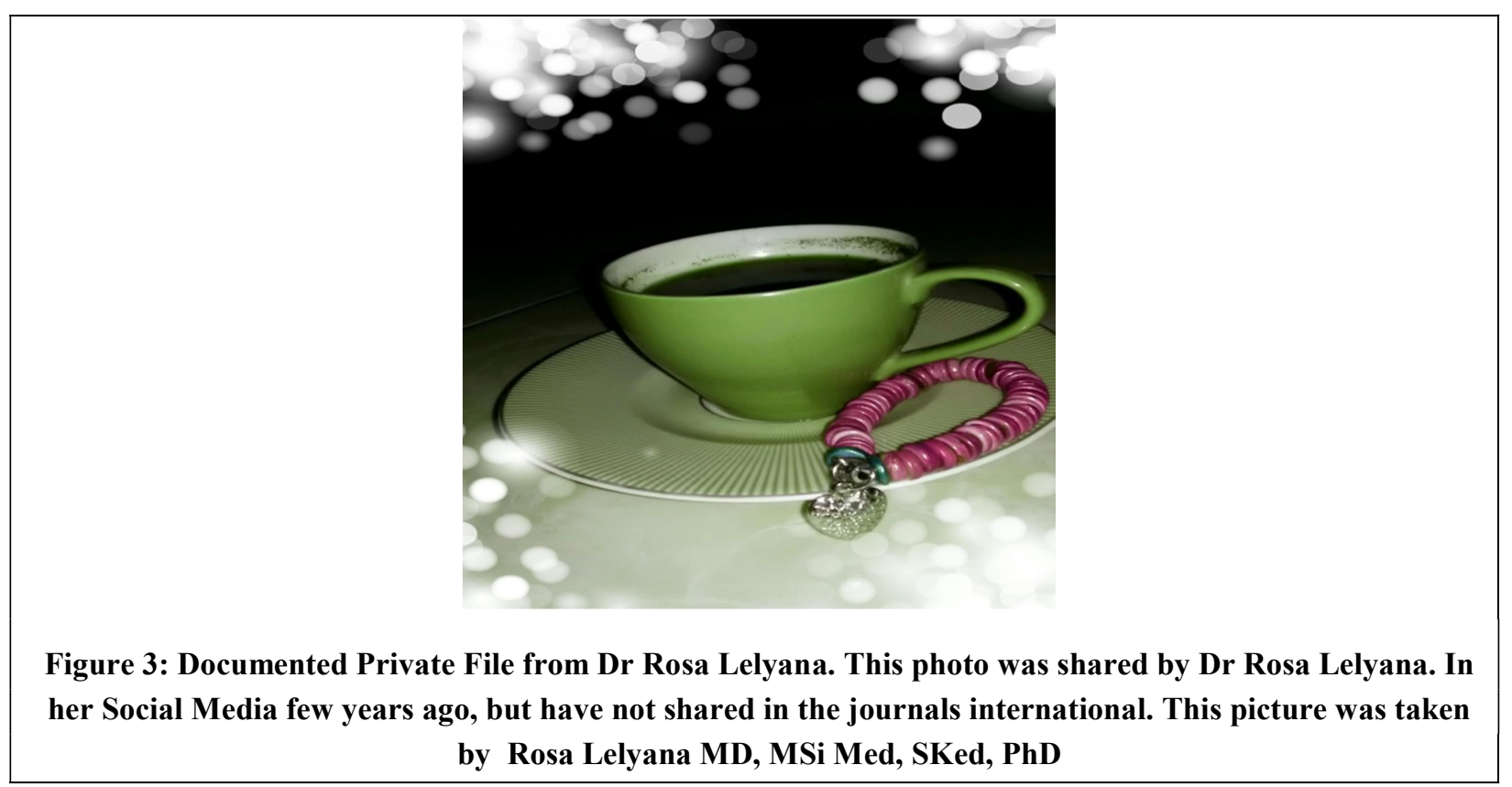

Coffee consumption should be done 2 cups per day, without sugar to be drunk in the morning and afternoon when our bodies need better stamina.

Water is water that is needed by the body as a drink. Water consumption apparently affects IL-10 levels according to the components contained in drinking water. IL-10 belongs to a family of cytokines [12]. The results of previous studies related to water consumption showed that water compared to coffee water did not prove a significant difference between giving coffee water and water to the difference in the mean levels of IL-10 in the group of obese and non-obese rats. This means that there is no difference between the consumption of water and water containing coffee on IL-10 levels. So there are similarities between plain water and coffee water on IL-10 levels [12].

In addition, the group that consumed coffee drinks decreased IL-10 levels less than the control group who consumed water. This shows that coffee water is better than plain water because coffee water does not significantly reduce IL10 levels [12]. It is well known that IL-10 is an anti-inflammatory cytokine that is required to fight proinflammatory conditions. So, if IL-10 levels decrease less after drinking coffee than drinking water, it shows that coffee water is better consumed than plain water in reducing IL-10 levels because coffee water is not excessive in lowering IL-10 levels. Where IL-10 as an anti-inflammatory is needed by the body in fighting pro-inflammatory conditions, although IL-10 levels should not be excessive in the body. As the results of a study showed that high IL10 levels $>169,96 \mathrm{pg} \mathrm{ml-11}$ had a bad prognosis [12-14] so it was better to drink water if you wanted to reduce IL10 levels that were too high. In fact, IL-10 also plays an important role in initiating and promoting malignant cell types [15]. The study showed that water is better consumed in lowering IL-10 levels that are too high. So, although drinking water will reduce IL-10 levels, as well as when drinking coffee water, clinically the decrease in IL-10 levels is better in someone who consumes coffee water than plain water. Consumption of coffee water will reduce levels of IL-10 slightly. Consumption of water will reduce IL-10 more in the body. So it is feared that IL-10 levels will drop once when consuming water than when drinking coffee because IL-10 is needed by the body under normal 
conditions [12].

Regular drinking water without coffee will reduce IL-10 levels 3-4 times more than coffee water, and this is not good for the body, because IL-10 is needed by the body in normal levels.

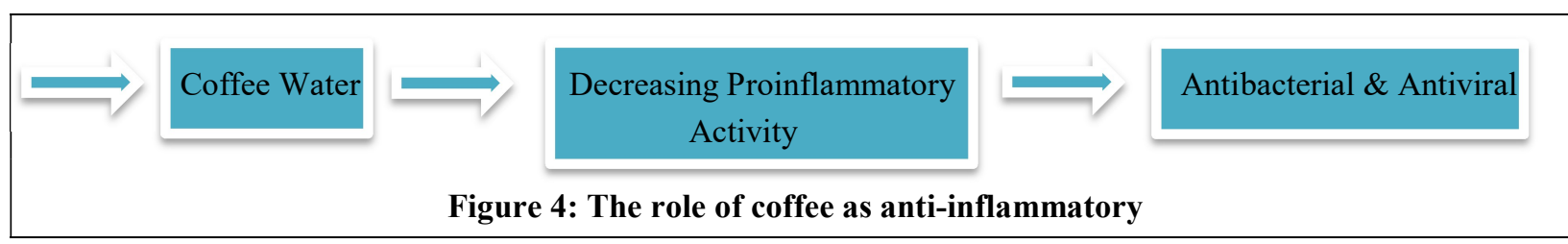

Rosa Lelyana's research (2015) showed that the mean difference between all rats that drank coffee and all control rats that received water showed a significant difference in IL-10 levels $(z=-2.309 ; p<0.05)$. This means that there is a lot of decrease in IL-10 levels in control rats that only consume water and food with a limited number of calories (mean difference in control group $=-3.31$ ). Meanwhile, mice that consumed coffee water with food with limited calorie consumption only experienced a slight decrease in IL-10 levels (mean difference in treatment group $=-0.77$ ). This proves that coffee consumption is only able to slightly regulate the decrease in IL-10 levels, while water consumption is able to lower IL-10 levels more than coffee consumption. So that the immune system of coffee consumers is better than the immune system of water consumers because water consumers experience low levels of IL-10 [12].

\section{Water Content for Preventing Skin Ageing Related to IL-10 Level for Human Health}

In addition to the above benefits, water is also important to prevent skin aging because water consumption does affect the normal physiology of the skin. [16] The role of water in the prevention of dehydration is to maintain a balance of body fluid volume between intracellular and extracellular fluids of the body [16, 17]. Water affects the levels of IL-10 in the body, and then affects the condition of the skin barrier so that the skin has sufficient water content which results in healthier-looking skin.

As with psoriasis, where the skin is deficient in IL-10 expression, it was found that the application of IL-10 cytokines in psoriasis can be used as a therapy [18]. So, low levels of IL-10 will reduce skin health [18]. So that too much water consumption will reduce IL-10 levels [12], where too much IL-10 decrease will have a bad impact on psoriasis sufferers due to IL-10 deficiency.

Finally, it was concluded that it is better for psoriasis sufferers to consume coffee because it will not aggravate the condition of IL-10 deficiency in psoriasis. This will also help cure psoriasis sufferers. It is also recommended to reduce the consumption of water because it will increase the decrease in IL-10 levels so that the body of psoriasis sufferers will increasingly experience IL-10 deficiency, as a result, the psoriasis condition will get worse

So, consuming coffee drinks will increase IL-10 levels as well as increase coffee's antioxidant and antiinflammatory activity $[11,12]$ so that IL-10 deficiency in psoriasis skin conditions will be improved by coffee consumption.

In addition, coffee does not reduce IL-10 levels much [12] so that it does not worsen the psoriasis condition, but the psoriasis condition is improved by the presence of coffee which is healthy for the body and skin.

\section{Water Content for taking a bath Related to IL-10 Level for Human Health}

D.1 Air mandi mengandung Sulphur (S)

Another benefit of water for the body is the water used for bathing. Some people sometimes use hot water, even bathing using hot springs containing sulfur for bathing as a form of therapy recommended by some health experts in patients with recurrent infections. However, the results of a study showed that the use of hot sulfuric water in fact showed an increase in IL-10 levels in the saliva of users of hot sulfuric water for bathing [19]. Because heat and 
sulfur stimulate an increase in pro-inflammatory activity so that anti-inflammatory levels of IL-10 increase after a hot sulfur bath. An increase in anti-inflammatory activity due to hot sulfur baths is an inflammation caused by traumatic conditions of the body due to thermal chemicals that are not caused by the presence of viruses or bacteria. So it can be concluded that taking a hot shower too often is not good for the body because it will cause a chronic inflammatory process due to thermal/hot temperatures. Similarly, bathing in water containing sulfur or sulfur is also not good for the body because it will cause an inflammatory process for the body/pro-inflammatory due to chemical sulfur, especially if done too often. Hot showers and sulfur baths will increase proinflammatory conditions for the body or an inflammatory process for the body thereby increasing the anti-inflammatory cytokine IL-10 [19]. Of course, IL-10 levels that increase excessively for the body after taking a hot sulfuric bath due to the thermal inflammatory process are not good because IL-10 levels have normal levels in the body.

D.2 Bathwater contains hydrogen $(\mathrm{H})$

Dendritic cells or dendritic cells (DCs) are the gatekeepers of the immune system that control specific immune responses. Among the cytokines produced by tolerogenic DCs, IL-10 is a cytokine that plays a key role in regulating $\mathrm{T}$ cell excess in response to microbial pathogens to prevent tissue damage and chronic inflammation. IL-10 also functions as an inhibitor of activated macrophages and as mentioned above as dendritic cells [20]. Serum cytokine levels such as IL-10 and TNF- $\alpha$ were significantly reduced in mice given hydrogen water. This study also demonstrated that hydrogen water affects allergic contact dermatitis via Th1 and Th2-responsive modulation pathways in NC/Nga mice. So the consumption of hydrogen water can reduce levels of IL-10 [21] so as not to overdose it in the body.

\section{E. Water Content for Preventing Dehydration Related to IL-10 Level for Human Health}

E.1 The water component contains electrolytes

Adequate fluid consumption and hydration in children are important for physiological reasons and for the health of the body and for maintaining good habits of consuming water. The quality and quantity of drinks consumed by children also need attention because it is important, examples of consumption of sugar and sweetened drinks and fruit juices need attention [22].

Water is indeed an important substance that the body needs. Similarly, fluid and electrolyte balance is important to maintain the function of thinking and support one's physical condition, especially in a very hot environment. This is proven in a study that the levels of $\mathrm{Hb}, \mathrm{Ht}$, blood viscosity, blood sodium levels of a person's body are significantly different between body conditions in a hot environment and a cold environment. Where levels of $\mathrm{Hb}, \mathrm{Ht}$, and the viscosity of a person's blood in a hot environment will be of low value. Meanwhile, sodium levels, USG/Urine Specific Gravity, pH, urine sodium, urine potassium, and urinary chloride levels were higher in research subjects who consumed electrolyte drinks than plain water. This study proves that the consumption of electrolyte drinks in hot environmental conditions will help improve hydration status and body electrolyte levels [23].

\section{E.2 Components of water in food and drink}

Water is also contained in various beverages and foods in various percentages, for example, watermelon contains 90-99\% water, while fruit juices contain $80-89 \%$ water, even cooked corn contains $70-79 \%$ water, as well as baked potatoes still contain $70-79 \%$ water. But pizza only contains $40 \%$ water, so does bread contain $30-39 \%$ water. Butter contains only $10-19 \%$ water. Some foods that contain little water are chocolate chip cookies, crackers, and cereals and dry roasted nuts contain only $1-9 \%$ water. While foods that do not contain water are sugar and oil [24].

\section{E.3 Water component for athletes}

Consumption of water is needed by the body. Likewise, an athlete needs to maintain the condition of body fluids. In a study conducted on several healthy men with euhydrated and moderately hypohydrated conditions showed that IL- 
10 levels increased significantly after the exercise. This indicates that prolonged exercise or exercise will trigger the release of anti-inflammatory cytokines that respond to antigens due to the production of pro-inflammatory cytokines that appear after acute stress conditions due to exercise [25].

\section{F. Water Content for regulating body core temperature related to IL-10 Level for Human Health}

Water is needed to maintain body temperature. However, a study conducted on tennis athletes showed that fluid consumption was not associated with average body temperature. Similarly, fluid retention, sweat loss, and changes in body weight percentage were also not associated with average body temperature [26]. However, the results of previous studies suggest that insufficient water will result in dehydration, thereby increasing the risk of serious illness $[27,28]$ and being able to affect body temperature. When dehydration occurs more than $2 \%$ of body weight loss $(\sim 1.5 \mathrm{~L})$, then a person's performance will decrease or cause a person to experience illness. This is exacerbated by environmental conditions that result in heat stress [28, 29]. In sick conditions, the role of IL-10 is very important because IL-10 as an anti-inflammatory cytokine has the potential to limit the heat response, especially when the body is infected by gram-positive and gram-negative [30].

IL-10 is related to IL-6, where there is a change in serum IL-6 levels with a 1 (one) ${ }^{\circ}$ increase in body temperature stimulated by heat from the lower body area. This may be influenced by peripheral temperature (such as body muscles) and adrenaline [31]. IL-10 is an anti-inflammatory cytokine that inhibits the action of proinflammatory cytokines where pro-inflammatory cytokines affect fever, so IL-10 as an anti-inflammatory cytokine functions as an antipyretic in regulating fever [32]. The action of IL-10 is also influenced by the water content contained in food and drink or water used in bathing and cosmetic products used daily.

IL-10 as an anti-inflammatory is very necessary for the body to fight pro-inflammatory conditions, so regulating IL10 levels to be within normal values is very important because levels of IL-10 as a pro-inflammatory cytokine that exceed normal values indicate a disease condition or dysregulation of the body's defense system [33]. IL-10 levels are strongly influenced by the consumption of food and beverages, the use of water in daily life, especially when bathing and cosmetic products used daily. The role of water in influencing IL-10 levels so that it is able to regulate body temperature so that the body remains in a healthy condition is very important. Even the level of IL-10 in the body is capable of acting as an antipyretic [33]. Therefore, adequate water consumption can reduce high body temperature through the role of IL-10, so we must always consume enough water for our lives to keep our bodies healthy [33]. Other studies also support this study, that water consumption is important for the body. In fact, although the consumption of water containing coffee is also important for the body because coffee consumption is also able to help increase NO levels, decrease levels of xanthine oxidase, TNF-, and reduce the diameter of adipose cells and play a role in reducing weight as anti-obesity [34]. The results of this study support that water consumption affects IL-10 levels, because NO, XO, TNF- $\alpha$, and adipose tissue are associated with IL-10 levels in the body [12, 34].

\section{Conclusions}

Health is very important for the body. One of the things that affect the health of the body is the consumption of water. Water is needed by the body. Water is found in various food and beverage sources as well as cosmetic products as well as water content when we bathe. Water affects IL-10 levels in the body so that it can affect the health condition of our bodies through various kinds of body activities. Similarly, the regulation of body temperature.

\section{DECLARATIONS}

\section{Funding}

This research did not receive any specific grant from funding agencies in the public, commercial, or not-for-profit sectors. 


\section{Conflicts of Interest}

The authors declared no potential conflicts of interest with respect to the research, authorship, and/or publication of this article.

\section{Acknowledgment}

Thank you to my senior lecturer, my father Prof Dr. Soebowo, SpPA, and my family, and people who support this research and especially for Selinus University, Italia who support my dissertation related to this research

\section{REFERENCES}

[1] Amy B. Understanding Food Principles and Preparation. 5th Ed. Chapter 3 Chemistry of Food Composition. Publisher Belmont, CA: Thomson/Wadsworth.(2008) page 32-3. ISBN 0-495-11910-5 978-0-495-11910-4.

[2] Popkin BM, D’Anci KE, Rosenberg IH. Water, Hydration and Health. Nutr Rev. (2010) 68(8): 439-58. 10.1111/j.1753-4887.2010.00304.x

[3] Rumiyati R, Sismindari S, Endang S, Sitarina W, Dewi TS, Brilliant KA, et . Cytoprotective activity of carrot and tomato callus extracts and the ex-pressionof cytokines in UVirradiated fibroblast cells. Indonesian Journal of Biotechnology (2019) 24(2). 10.22146/ijbiotech.51734

[4] Andersen V, Egeberg R, Tjonneland A, Vogel U. Interaction between IL-10 polymorphisms and dietary fibre in relation to risk of colorectal cancer in a Danish case cohort study. BMC Cancer. (2012); 12:183. 10.1186/1471-2407$12-183$

[5] Hazewindus M, Haenen GRMM, Weseler AR, Bast A. Protection against Chemotaxis in the Anti-Inflammatory Effect of Bioactives from Tomato Ketchup. PLoS One.(2014) 9 (12):e114387. 10.1371/journal.pone.0114387.

[6] Palozza P, Parrone N, Simone RE, Catalano A (2010).Lycopene in atherosclerosis prevention: an integrated scheme of the potential mechanisms of action from cell culture studies. Arch Biochem Biophys. (2010) 504 (1):26-33. 10.1016/j.abb.2010.06.031 (PubMed) (Google Scholar).

[7] Palozza P, Parrone N, Simone R,Catalano A (2011). Role of lycopene in the control of ROS mediated cell growth: implications in cancer prevention. Curr Med Chem (2011); 18(12):1846-60. 10.2174/092986711795496845 (PubMed) (Google Scholar).

[8] Hayden MS, West AP, Ghosh S.NF-kappaB and the immune response. Oncogene.(2006);25(51):675880.10.1038/sj.onc1209943.(PubMed)(Google Scholar).

[9] Christman JW, Blackwell TS, Juurlink BH. Redox regulation of nuclear factor kappa B: therapeutic potential for attenuating inflammatory responses. Brain Pathol. (2000) 10:153-62.10.1111/j.1750-3639.2000.tb00252.x(PubMed) (Google Scholar)

[10] Frusciante L, Carli P, Ercolano MR, Pernice R,Di Mateo A, et al.Antioxidant nutritional quality of tomato. Mol Nutr Food Res. (2007); 51(5):609-17. 10.1002/mnfr.200600158 (PubMed)(Google Scholar).

[11] Rosa Lelyana. Effect of Coffee Daily Consumption for Uric Acid Level and Body Weight to Prevent Metabolic Syndrome. J Journal of Nanomedicine and Nanotechnology (2016) 7 (5).400. 10.4172/2157-7439.1000400.

[12] Lelyana R (2020) The Effect of 2 Cup Daily Coffee Consumption on the IL-10 Levels of Obese and Non Obese Male Wistar Rats. J Nanomed Nanotech Nanomat. 1: 102.

[13] Fickenscher H, Hor S, Kupers H, Knappe A, Wittmann S, Sticht H. The interleukin -10 family of cytokines: Review study .Trends Immunol.2002;23(2):89-96. 10.1016/s1471-4906(01)02149-4.

[14] Wang H, Wang L, Chi PD, Wang Wd, Chen Xq, Geng Qr, Xia Xj \& Lu Y . High level of interleukin-10 in serum predicts poor prognosis in multiple myeloma. Br J Cancer. 2016; 114(4): 463-468. 10.1038/bjc.2016.11

[15] Holland G, Zlotnik A.Interleukin-10 and cancer. Cancer Invest.1993; 11(6): 751-8. 10.3109/07357909309046950.

[16] Palma L, Marques LT, Bujan J, and Rodrigues LM. Dietary water affects human skin hydration and biomechanics. Clin Cosmet Investig Dermatol. 2015; 8: 413-21. Published 2015 Aug 3. 10.2147/CCID.S86822.

[17] Ritz P, Berrut G. The importance of good hydration for day-to-day health. Nutr Rev. 2005; 63(6 Pt 2):S6-S13. 10.1111/j.1753-4887.2005.tb00155.x. 
[18] Asadullah K, Sterry W, Volk HD. Interleukin-10 and Psoriasis .In: Madame Curie Bioscience Database (Internet). Austin (TX): Landes Bioscience; 2000-2013.

[19] Prandelli C, Parola C, BuizzaL, DelBarba A. Marziano M, Salvi V, et al. Sulphurous Thermal Water Increases the Release of the Anti-Inflammatory Cytokine IL-10 and Modulates Antioxidant Enzyme Activity. Article (PDF Available) in International journal of Immunopathology and Pharmacology. 2013; 26(3):633-46. $10.1177 / 039463201302600307$

[20] Schülke S. Induction of Interleukin-10 Producing Dendritic Cells As a Tool to Suppress Allergen-Specific T Helper 2 Responses. Front Immunol. 2018; 9: 455. Published 2018 Mar 19. 10.3389/fimmu.2018.00455.

[21] Ignacio RM, Kwak HS, Yun YU, Sajo MEJV, Yoon YS, Kim CS, et al. The Drinking Effect of Hydrogen Water on Atopic Dermatitis Induced by Dermatophagoides farinae Allergen in NC/Nga Mice. Evid Based Complement Alternat Med. 2013; 2013:538673. 10.1155/2013/538673.

[22] Bottin JH, Morin C, Guelinckx I, Perrier ET. Hydration in Children: What Do We Know and Why Does it Matter?.Ann Nutr Metab.2019;74(suppl 3):11-8. 10.1159/000500340.

[23] Illyas EII, Bardosono S, Surapsari J, Freisleben HJ. Effects of Electrolite Beverage on Preventing Dehydration among Workers in Different Environmental Temperature. World Nutrition Journal. 2018; 1 (2). Worldnutrijournal.org 10.25220/WNJ.V01i2

[24] Barry M.Popkin, Kristen E.D’Anci, Irwin H. Rosenberg. Water, Hydration and Health. Nutrition Reviews.www.ncbi.nlm.nih.gov.

[25] Ida S. Svendsen, Sophie C Killer, Michael Gleeson. Influence of Hydration Status on Changes in Plasma Cortisol, Leukocytes, and Antigen-Stimulated Cytokine Production by Whole Blood Culture following prolonged exercise. International Scholarly Research Notices Hindawi. 2014; p.1-10.https://doi.org/10.1155/2014/561401.

[26] MF Bergeron, JL Waler, EL Marinik (2006) Volintary fluid intake and core temperature responses in asolescent tennis players: sports beverage versus water. Br J Sports Med. 2006; 40(5): 406-10. www.ncbi.nlm.nih.gov doi: 10.1136/bjsm.2005.023333.

[27] Body temperature regulation.Nestle Waters.www.nestle-waters.com.

[28] Nisha Charkoudian, Robert W. Kenedick, Anthony J Lapadula,Albert J Swiston, Tajesh Patel, Laurie A.Blanchard, et al.(2016)Planning Military Drinking Water Needs: Development of a User-Friendly Smart Device Application. Military Medicine, 181, 9:1142. Downloaded from https://academic.oup.com/milmed/articleabstract/181/9/1142/4159826 by Rosa Lelyana on 27 July 2020

[29] Kenefick RW, Cheuvront SN, Palombo LJ, Ely BR, Sawka MN. Skin temperature modifies the impact of hypohydration on aerobic performance. J Appl Physiol. 2010; 109:79-86. 10.1152/japplphysiol.00135.2010.

[30] T Cartmell, C Ball, AF Bristow, D Mitchell, S Poole. Endogenous interleukin-10 is required for the defervescence of fever evoked by local lipopolysaccharide-induced and Staphylococcus aureus-induced inflammation in rats. J Physiol. (2003)Jun 1;549(Pt 2) : 653-64 .Published online 2003 Apr 11. 10.1113/ jphysiol.2002.037291 www.ncbi.nlm.nih.gov

[31] Takamasa Hashizaki, Yukihide Nishimura, Kenzo Teramura, Yasunori Umemoto, Manabu Shibasaki, CA Leicht, et al. Differences in serum IL-6 response after $1{ }^{\circ} \mathrm{C}$ rise in core body temperature in individuals with spinal cord injury and cervical spinal cord injury during local heat stress. Int J of Hyperthermia. (2018); 35 (1). p 541-7.

[32] Lisa R Leon, Wieslaw Kozak, Karin Rudolph, Matt J Kluger.An antipyretic role for interleukin-10 in LPS fever in mice.The American J of Physiol.1999; 276 (1 Pt2):R81-9.

[33] Warren E Rose, Jens C Eickhoff, Sanjay K Shukla, Madhulatha Pantrangi, Suzan Rooijakkers, Sara E Cosgrove, et al. Elevated serum interleukin-10 at time of hospital admission is predictive of mortality in patients with Staphylococcus aureus bacteremia. J Infect Dis. (2012); 206(10):1604-11. 10.1093/infdis/jis552.Epub 2012 Sep 10.

[34] Rosa Lelyana Soebowo.(2020). Dissertation: Coffee Consumption as Antiobesity. Selinus University, Italia. 1:33-50. 